\title{
MISCELANEA
}

COMUNICACIÓN ORAL VII CONGRESO NACIONAL DE LA SOCIEDAD CIENTÍFICA ESPAÑOLA DE ENFERMERÍA - SCELE. Mayo de 2014. UNIVERSIDAD DE ALICANTE.

\section{IMPACTO DEL DIAGNÓSTICO DE DIABETES TIPO 1 en NIÑOS Y ADOLESCENTES}

\section{IMPACT OF DIAGNOSIS OF TYPE 1 DIABETES IN} CHILDREN AND ADOLESCENTS

Isla Pera P., Insa Soria R.

EUI. Universitat Barcelona/Unidad educación diabetes. Hospital Belvitge.

Contacto: pisla@ub.edu rinsa@ub.edu 


\section{Palabras clave:}

diabetes tipo 1, infancia y adolescencia, familia, investigación cualitativa.

\section{OBJETIVO:}

Conocer el impacto personal y familiar del diagnóstico de diabetes tipo 1 (DM1) en niños y adolescentes.

\section{MÉTODO:}

Etnografía enfocada. Sujetos: Muestreo intencional formado por 20 pacientes y 10 familiares. Recogida de datos: Observación participante y entrevistas semiestructuradas. Análisis de datos: Los datos, se organizaron en unidades, categorías, temas y subtemas utilizando las 4 etapas descritas por Ritchie, Spencer y O'connor (2003). Las investigadoras realizaron un proceso de reflexividad intentando que sus experiencias y creencias no interfirieran en la interpretación de los resultados.

\section{RESULTADOS:}

Significado de la enfermedad: Los enfermos y familiares describen la enfermedad como algo que se infiltra en el cuerpo de las personas y modifica la existencia. El diagnóstico de DM1 genera percepción de gravedad y de injusticia. La pregunta de "qué hice yo para merecer esto en esa edad" o "porqué me tuvo que pasar a mí", es frecuente. El mayor impacto se produce en la adolescencia.

Control de la enfermedad: Tanto los enfermos como los familiares expresan el sacrificio que impone seguir las recomendaciones y las dificultades de mantener un control metabólico estable. Algunos enfermos perciben más amenazante el tratamiento y control exigido que la enfermedad porque piensan que disminuyen sus posibilidades de vivir una vida placentera similar a la de su grupo de referencia.

La familia: Todos los informantes reconocen a la madre como la cuidadora principal (CP). El cuidado del niño con DM1 se convierte en el eje central de la vida familiar desde el momento del diagnóstico. Esta forma de cuidar conlleva una elevada carga física y mental para la CP que se acompaña de manifestaciones físicas y emocionales intensas. La mayoría de los pacientes reconocen que la familia y fundamentalmente la madre, viven el proceso del diagnóstico de la DM1 con más ansiedad que ellos mismos.

Relación con los profesionales sanitarios: Los enfermos y familiares valoran el conocimiento médico pero dan mucha importancia a la relación terapéutica. Reconocen que la relación profesional y usuario requiere atención especializada, cuidados, apoyo, asesoramiento y un nivel adecuado de confianza mutua.

\section{CONCLUSIONES:}

El diagnostico de DM1 implica afrontar una enfermedad incurable que exige, además del tratamiento farmacológico, una forma de vida óptima y saludable que requiere cambios en los patrones culturales. Se produce una ruptura con la vida familiar anterior y un replanteamiento del futuro que está condicionado por el cuidado, control y educación del enfermo, relaciones con hermanos y grupo familiar, relaciones sociales (escuela, amigos, ocio), posibles limitaciones y amenaza constante de posibles complicaciones.

La educación terapéutica dirigida al empoderamiento del paciente y de la familia y unas relaciones profesional y usuario basadas en la confianza y en la relación de ayuda son necesarias para favorecer la adaptación a la nueva situación. 